\title{
Effect of Surface Pretreatment on the Cormosion Resistance of Epoxy-Coated Carbon Steel
}

\author{
DongHo Lee, JinHwan Park, and MinYoung Shon ${ }^{\dagger}$ \\ Protective coating and Corrosion center, Department of Industrial Chemistry, Pukyong National University, \\ San 100, Yongdang-Dong, Nam-Gu, Busan, 608-739, Korea
}

(Received September 3, 2012; Revised October 29, 2012; Accepted October 29, 2012)

\begin{abstract}
The corrosion resistance of epoxy-coated carbon steel was evaluated. The carbon steel surface was subjected to different treatment methods such as steel grit blasting with different size, steel shot ball blasting and power tool treatment. To study the effect of the treatments, the topology of the treated surface was observed by optical 3D microscopy and a pull-off adhesion test was conducted. The corrosion resistance of the epoxy-coated carbon steel was further examined by electrochemical impedance spectroscopy (EIS) combined with hygrothermal cyclic testing. The results of EIS indicated that the epoxy-coated carbon steel treated with steel grit blasting showed an improved corrosion resistance compared to untreated epoxy-coated surfaces or surfaces subjected to shot ball blasting and power tool treatments.
\end{abstract}

Keywords : EIS, Epoxy, Blasting, Hygrothermal, Adhesion

\section{Introduction}

The corrosion is a general phenomenon which is widely observed in metal structure. The corrosion protection of carbon steel has been an interesting subject of many researchers. However, the effective corrosion protection methods are still investigated. The most widely used method for metal protecting against corrosion is coating, especially an organic coating. The corrosion protection mechanism associated with organic coatings is barrier protection and the main role of coating is to give a physical barrier against corrosive species, such as $\mathrm{H}_{2} \mathrm{O}, \mathrm{O}_{2}$ and $\mathrm{Cl}^{-}$, etc However, there are no permanently impermeable organic coatings regarding corrosive species and when defect occur, corrosive species can reach the metal surface and then corrosion can be generated.

Epoxy is one of the most common barrier coating material used in severe corrosion environments including marine environment. ${ }^{1), 2)}$ Due to the hydrophilic chemical groups of cured epoxy structure such as hydroxyl group $(-\mathrm{OH})$, carboxyl group $(\mathrm{C}=\mathrm{O})$ and amino group $(\mathrm{N}-\mathrm{H})$ that have unpaired electron, epoxy has exhibited the hydrophilic properties by attracting water from the environment $^{3)-6)}$ to which it is exposed, resulting in a decrease in its corrosion protection for metal underneath. Accordingly,

\footnotetext{
${ }^{\dagger}$ Corresponding author: myshon@pknu.ac.kr
}

there have been a lot of efforts to improve the protectiveness of epoxy coating materials, considering their coating thickness and surface treatment, etc.

The mechanical surface treatment of metals is an essential step and significantly affects the adhesion strength of coatings and adhesives. A number of studies have examined the effect of mechanical surface treatment on the strength and durability of adhesive joints using various adherents and adhesives. ${ }^{77-13)}$ Sancaktar and Gomatam reported that roughening the surface, removing the weak surface layers, and increasing the reactivity of the surface led to the improvement of adhesion strength. ${ }^{14)}$ Shahid and Hashim reported that most surface treatments give rise to surface roughness and that, in general, the most effective treatment method to achieve the desired level of surface roughness and adhesion strength was grit blasting. ${ }^{15)}$ Grit blasting not only removes weak surface layers but also changes the chemical properties of the substrate. ${ }^{13)}$ However, the number of studies that relate surface roughness to the corrosion protection of epoxy-coated carbon steel under corrosive conditions is limited.

The objective of the present work is to develop an efficient epoxy coating system by employing different surface treatments such as steel grit blasting, steel shot ball blasting, and power tool treatment and to examine the effects of surface roughness on the corrosion protectiveness of the epoxy coatings by using electrochemical impedance 
spectroscopy (EIS) combined with hygrothermal cyclic testing. ${ }^{16)-20)}$

\section{Experimental}

\subsection{Materials and preparation of epoxy specimens}

The diglycidyl ether of bisphenol A (DGEBA, supplied by Kumho P\&B Chemical, South Korea) and a polyamide epoxy adduct (PAEA, supplied by Kumho P\&B Chemical, South Korea) were used as the epoxy resin and curing agent, respectively. Xylene was used as a coating solvent. The molecular structures of the epoxy resin and the curing agent are depicted in Fig. 1.

The mixtures were vigorously stirred and degassed for $10 \mathrm{~min}$. Before coating, the surface of the carbon steel was treated by various surface treatments and degreased using acetone... The epoxy coatings were deposited on a carbon steel plate $(150 \times 70 \times 3 \mathrm{~mm})$ by air spraying resulting in a coating thickness of $150 \pm 10 \mu \mathrm{m}$ and then cured at 25 ${ }^{\circ} \mathrm{C}$ for 7 days at $60 \%$ relative humidity.

\subsection{Surface treatment and analysis}

Prior to epoxy coating, the surface of the carbon steel was mechanically treated by different techniques including steel grit blasting using two different grit sizes, steel shot ball treatment, and power tool treatment. For identification of the samples, the following terminology was adopted:

(1) NT: No surface treatment

(2) SB: Shot ball blasting with shot balls of $0.5 \mathrm{~mm}$ in diameter

(3) PT: Power tool treatment by mechanical disk grinder

(4) GS: Grit blasting with $0.4 \mathrm{~mm}$ diameter grits

(5) GL: Grit blasting with $0.8 \mathrm{~mm}$ diameter grits

After surface treatment, compressed dry air was blown across the surface to remove loose abrasive particles and dust, after which it was treated with acetone to remove any remaining oil or other contaminants. The technical specifications of the used steel grit, steel shot ball, and power tool are listed in Table 1, while SEM photographs of the abrasive materials are shown in Fig. 2. Surface topology was analyzed at $100 \times$ magnification by optical confocal 3D microscopy (Alicona, Germany) and the surface roughness was measured. The shape of the profile was examined by visual inspection.

\subsection{Adhesion properties}

Following the surface treatment, pull-off adhesion tests

Table 1. The technical specifications of the used steel grit, steel shot ball, and power tool

\begin{tabular}{cc}
\hline Terminology & Abrasives \\
\hline NT & No treatment \\
\hline SB & Steel shot ball blasting (diameter: $0.5 \mathrm{~mm}$ ) \\
\hline GL & Steel grit blasting (diameter: $0.8 \mathrm{~mm}$ ) \\
\hline GS & Steel grit blasting (diameter: $0.4 \mathrm{~mm}$ ) \\
\hline PT & Power tool (Grinder wheel) \\
\hline
\end{tabular}<smiles>CC(COc1ccc(C(C)(C)c2ccc(OCC(O)CC(C)Oc3ccc(C(C)(C)c4ccc(OCC5CO5)cc4)cc3)cc2)cc1)CC1CO1</smiles>
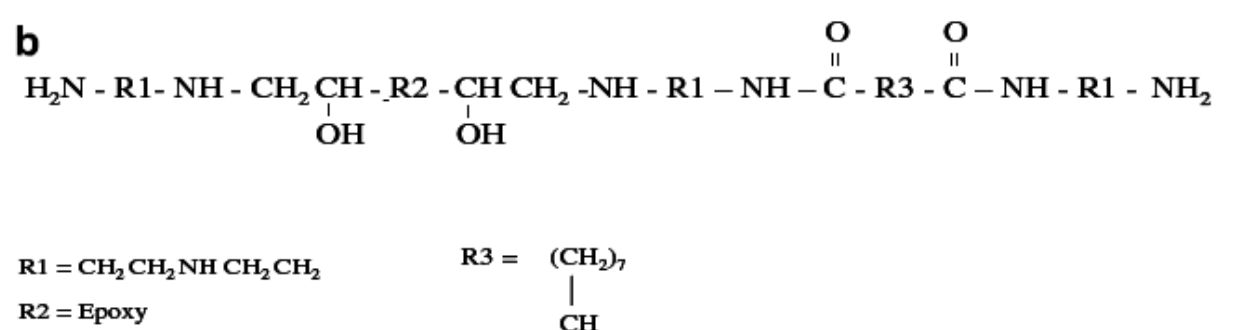<smiles>[R3]C1C=CC(CCCC)C(CC=CCCC)C1CCCC</smiles>

Fig. 1. Molecular structures of the epoxy coating system used in this study: (a) DEGBA, (b) PAEA. 


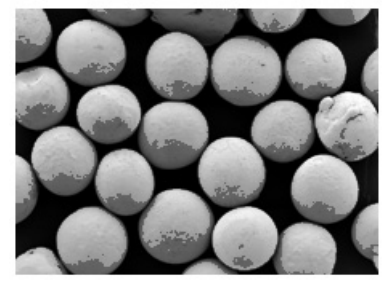

(a)

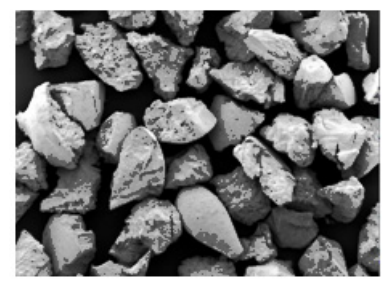

(c)

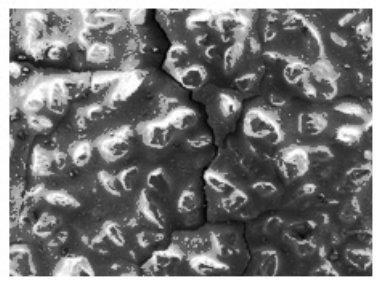

(b)

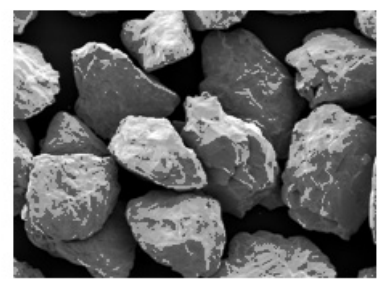

(d)
Fig. 2. SEM images of abrasives used in this study: (a) steel shot ball, (b) grinder wheel, (c) steel grit with $0.4 \mathrm{~mm}$ diameter and (d) steel grit with $0.8 \mathrm{~mm}$ diameter.

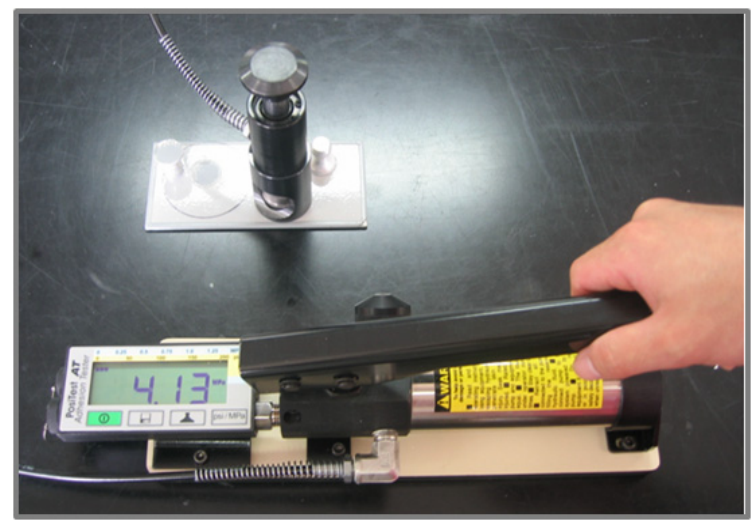

Fig. 3. Pull-off adhesion test equipment.

were performed to measure the adhesion strength of the epoxy coatings by the ASTM D 4541 standard method, ${ }^{21)}$ as shown in Fig. 3. A dolly fixture $20 \mathrm{~mm}$ in diameter was glued to the surface of the coated specimens using an epoxy adhesive. After complete curing of the adhesive, the fixture was loaded to the pull-off testing equipment (PA-0608, Defelsko Co) in terms of hygrothermal cyclic testing.

\subsection{Salt spray test}

The salt spray test was conducted by the ASTM B117 standard method. ${ }^{22)}$ Epoxy-coated carbon steel panels (75 $\times 150 \times 3 \mathrm{~mm}$ ) subjected to different types of surface treatment were placed in the salt spray chamber, and $0.5 \mathrm{~N}$ $\mathrm{NaCl}$ solution was prepared and sprayed using an atomizer.

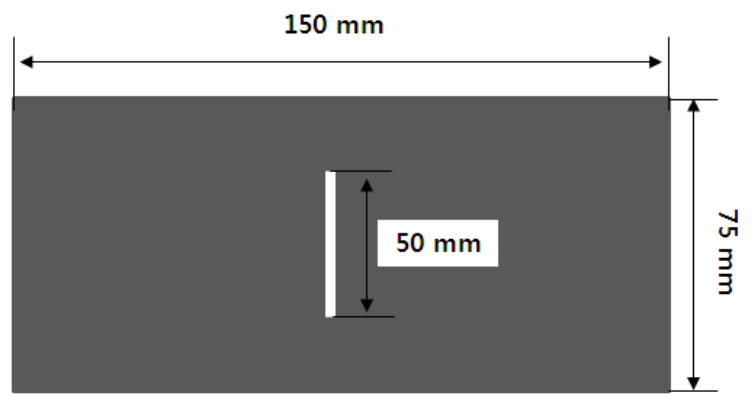

Fig. 4. The configuration of scribed coated specimens for undercutting evaluation.

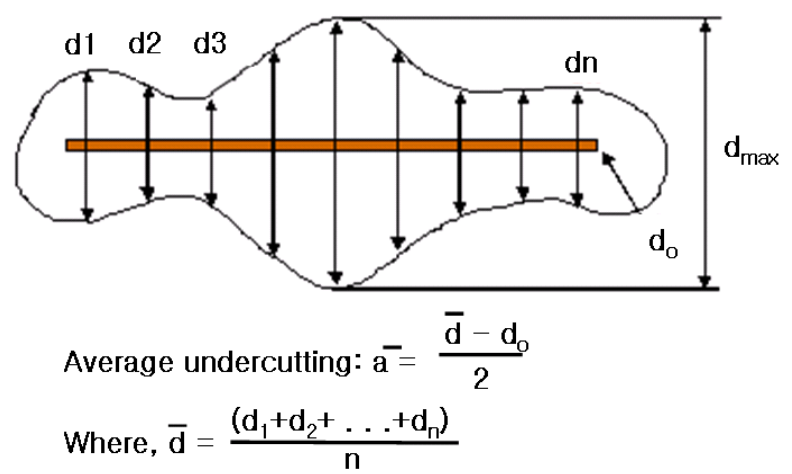

Fig. 5. Undercutting calculation based on Norsok standard M 501 .

During the test, the chamber was sealed air-tight and the temperature and humidity of the chamber were maintained at $35{ }^{\circ} \mathrm{C}$ and $97 \%$, respectively, throughout the test period of 5 weeks. The coated specimens were scribed by a knife over a length of $50 \mathrm{~mm}$ ( $2 \mathrm{~mm}$ in width, Fig. 4), and the surface condition of the coated panels was periodically observed by visual inspection to detect any surface change. The average undercutting at the scribe was calculated by the Norsok standard as shown in Fig. 5. ${ }^{23)}$

\subsection{Electrochemical cell and EIS combined with hygro- thermal cyclic test}

Hygrothermal cyclic tests were conducted to accelerate the cumulative effect of the electrolyte on the coating/carbon steel interface by the diffusion of the electrolyte into the coating. The thermal cycle program is shown in Fig. 6, after which the specimen was allowed to cool to room temperature.

After hygrothermal cyclic test, EIS test was performed at the open circuit potential, using an EG\&G 273A potentiostat and a Solartron1260 FRA impedance analyzer. The three-electrode electrochemical cell was used to conduct EIS consisted of the epoxy-coated carbon steel as the working electrode (exposed area: $13.9 \mathrm{~cm}^{2}$ ), a saturated 
calomel reference electrode, and a carbon counter electrode in $0.5 \mathrm{~N} \mathrm{NaCl}$ solution (Fig. 7). Impedance was measured by applying a sine wave of $50 \mathrm{mV}$ amplitude in a frequency range of $100 \mathrm{kHz}$ to $100 \mathrm{mHz}$.

\section{Results and Discussion}

\subsection{Surface analysis after surface treatment}

A change in the surface topology was observed after various surface treatments (Fig. 8 and 9). The optical confocal 3D microscopy results of the surface roughness measurements for the carbon steel surfaces treated by steel grit blasting, steel shot ball blasting, and power tools, are listed in Table 2. When inspecting the average surface

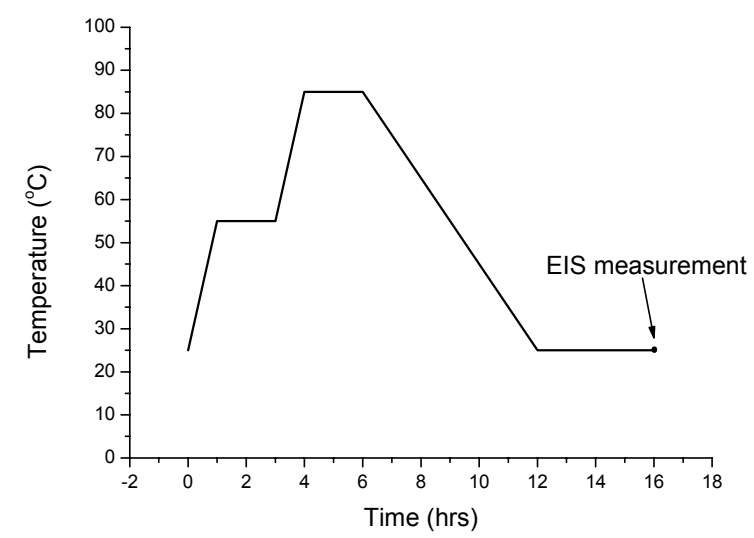

Fig. 6. Heating cycle used in the hygrothermal cyclic test.

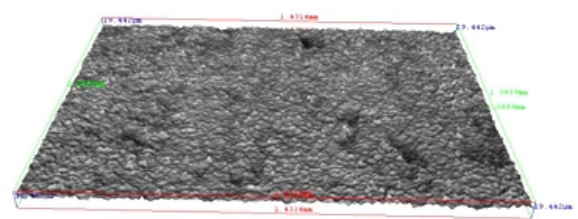

(a) roughness $\left(\mathrm{S}_{\mathrm{a}}\right)$ and maximum surface roughness $\left(\mathrm{S}_{\mathrm{z}}\right)$, it can be easily observed that the carbon steel surface without any surface treatment showed the smoothest surface. The GS-treated surface showed higher levels of average and maximum surface roughness than the SB-treated surface that employed particles of similar size. In addition, the profile features of the GS-treated surface showed an increased sharpness than the SB-treated surface. The rough and sharp profile obtained for the GS-treated sample is considered to provide a relatively high degree of mechanical interlocking or "keying" within the coating system.

The GL-treated surfaces showed similar levels of average surface roughness as that of the GS-treated surfaces, although the GL-treated surface showed a considerably

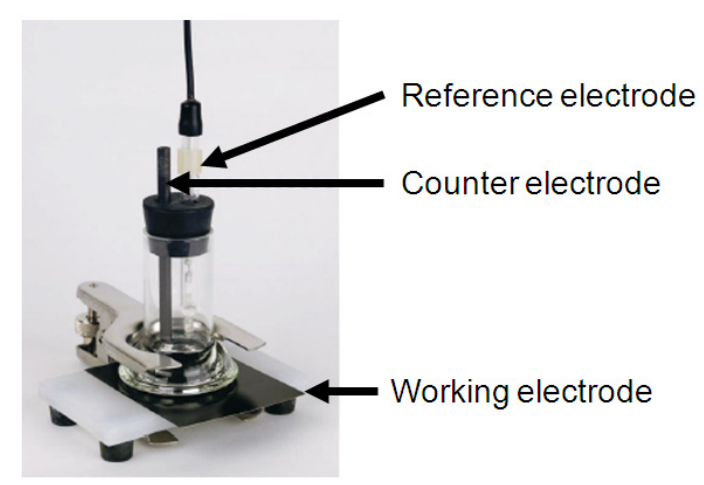

Fig. 7. Three-electrode electrochemical cell for EIS tests.

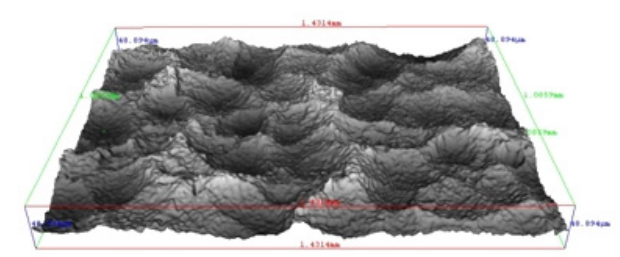

(b)

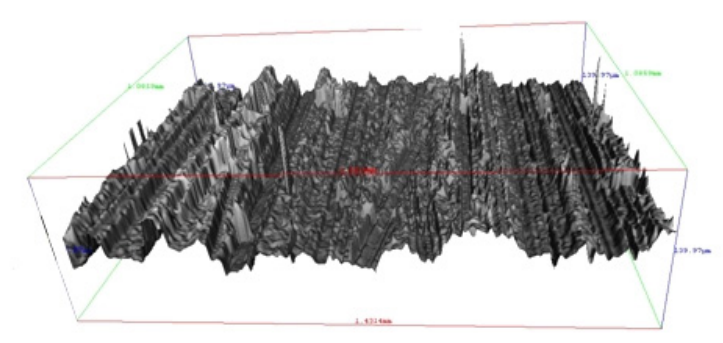

(c)

Fig. 8. Surface profile of carbon steel obtained by confocal 3D microscopy: (a) untreated, (b) SB treated and, (c) PT treated. 


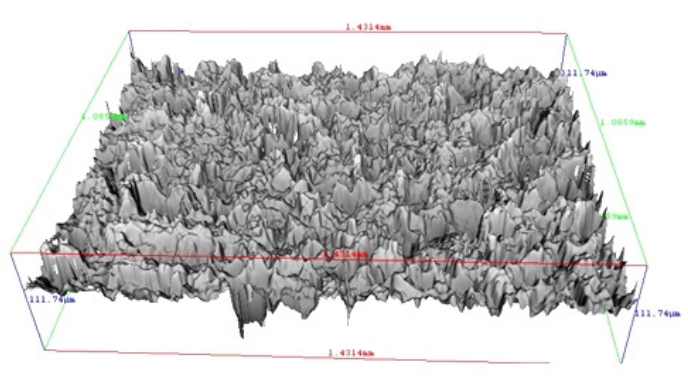

(a)

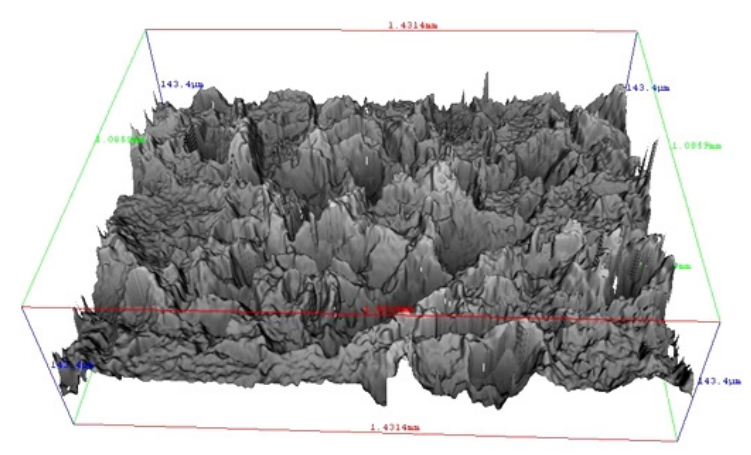

(b)

Fig. 9. Surface profile of carbon steel obtained by confocal 3D microscopy: (a) GS treated and (b) GL treated.

Table 2. The results of surface roughness measurement in terms of surface treatment methods test

\begin{tabular}{ccc}
\hline \multirow{2}{*}{ Surface treatment } & \multicolumn{2}{c}{ Surface roughness $(\mu \mathrm{m})$} \\
\cline { 2 - 3 } & $\mathrm{S}_{\mathrm{a}}$ & $\mathrm{S}_{\mathrm{z}}$ \\
\hline $\mathrm{NT}$ & 0.35 & 7.10 \\
\hline $\mathrm{SB}$ & 1.30 & 24.00 \\
\hline $\mathrm{GL}$ & 3.30 & 253.87 \\
\hline $\mathrm{GS}$ & 3.63 & 77.27 \\
\hline $\mathrm{PT}$ & 3.33 & 125.02 \\
\hline
\end{tabular}

higher maximum surface roughness. As compared to that of the GS-treated surfaces, the profile of the GL-treated surface was similarly sharp and rough, even though the size was different. Therefore, it might be difficult to predict the adhesion strength and corrosion protection for the GS- and GL-treated surfaces when only the roughness and shape of the surface are considered.

On the other hand, the PT-treated surfaces showed not only a very sharp profile but also some directionality (Fig. 8c) which is caused by the operation direction of the power tool. The average surface roughness of the PT-treated surface was similar to that of the GL- and GS-treated surface,

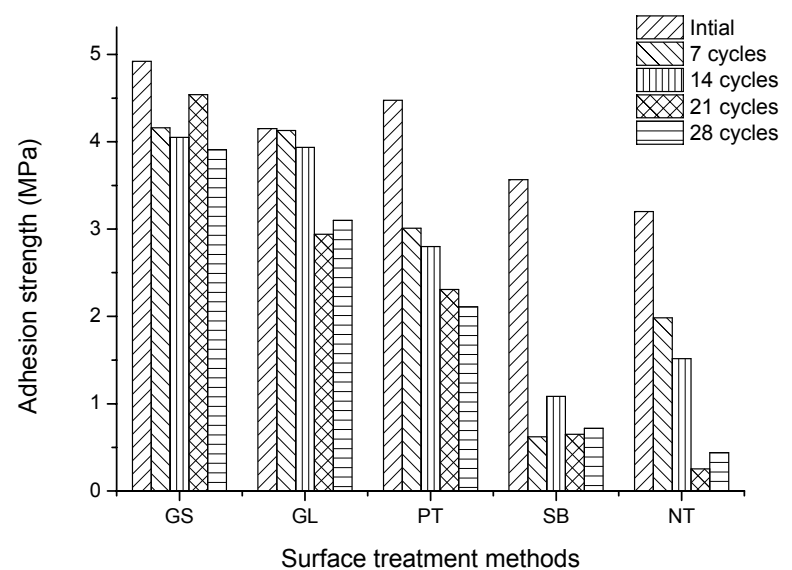

Fig. 10. Pull-off adhesion strength of the treated epoxy-coated carbon steel surface measured from hygrothermal cyclic tests.

and the maximum surface roughness was measured to be $125.02 \mu \mathrm{m}$.

\subsection{Effect of surface treatment methods on adhesion strength}

The results of the pull-off adhesion tests are shown in Fig. 10. Before hygrothermal cyclic testing, the adhesion strength of the untreated epoxy-coated surface showed the lowest value among the test group, followed by the SBtreated surface. The adhesion strength of the epoxy-coated GS-treated surface was of the highest value among those of the test group, while the epoxy-coated PT- and GLtreated surfaces showed slightly lower values.

The adhesion strength of the treated surfaces was decreased after hygrothermal cyclic testing. The adhesion strength after 28 cycles for the untreated epoxy-coated surfaces and the SB-treated surfaces decreased dramatically from 3.2 $\mathrm{MPa}$ to $0.44 \mathrm{MPa}$ and from $3.57 \mathrm{MPa}$ to 0.72 $\mathrm{MPa}$, respectively, while an interfacial failure mode was observed (Fig. 10). This clearly demonstrated that the smooth and rounded SB-treated surface was unsuitable for mechanical interlocking or keying with the coating, and a substantial loss in the mechanical interlocking effect was apparent with increasing hygrothermal cycles. In contrast, the adhesion strength of the epoxy-coated GS-treated surfaces only slightly decreased from 4.92 to $3.91 \mathrm{MPa}$ after 28 cycles of hygrothermal testing, and a partial cohesive and interfacial failure mode was observed after the pull-off test. In case of the GL- and PT-treated surfaces, the adhesion strength decreased from 4.15 to $3.10 \mathrm{MPa}$ and 4.48 to $2.11 \mathrm{MPa}$, respectively, after 28 test cycles. A partial cohesive and interfacial failure mode was observed in the epoxy coating of the GL-treated surfaces, while an interfacial failure mode was observed in the epoxy coating of 
the PT-treated surface. This clearly indicated that the sharp and rough surfaces were suitable for effective mechanical interlocking or keying with the coating and, furthermore, that the random directional profile in the GS- and GLtreated surfaces provided a higher adhesion strength than the directional profile in the PT-treated surface with an increase in the hygrothermal cycles.

\subsection{Effect of surface treatment on the undercutting at the scribe after the salt spray test}

If a coating is applied properly to a well-prepared steel surface and allowed to cure, corrosion across the intact paint surface is usually not of major concern. However, the corrosion behavior of epoxy coated metal is dramatically changed when it is scratched and exposed to the corrosive environment. The exposed metal at the centre of the scratch is readily accessible to oxygen and becomes cathodic. Anodes are then formed along the sides of the scratch where the paint, metal, and electrolyte penetrate and come into contact. Here, corrosion begins and spreads outwards from the scratch under the coating. The corrosion that begins in the scratch and spreads under the paint is called undercutting. Undercutting refers to the corrosion of the metal between the metal substrate and coating film at a sheared edge. A coating's ability to resist the spread of corrosion is of crucial importance.

The undercutting of the epoxy coating was examined to evaluate the effect of surface treatment on the corrosion protection of epoxy-coated carbon steel. Fig. 11 shows the undercutting results for specimens subjected to the salt spray test for 5 weeks. The specimens were cleaned with water, and the corrosion product was removed as it covered the surface. Once the samples were cleaned, surface defects such as blisters or rust could be identified. The measured undercutting of the untreated epoxy-coated steel surface was the highest at $11.58 \mathrm{~mm}$, which was slightly above that of the SB-treated surface $(8.68 \mathrm{~mm})$. These values were higher than that observed for the epoxy-coated specimens subjected to PT treatment $(5.00 \mathrm{~mm})$, GL treatment $(5.29 \mathrm{~mm})$, and GS treatment $(3.87 \mathrm{~mm})$.

Thus, it was confirmed that the degree of undercutting is related to the surface treatment methods before coating and, furthermore, that the GS treatment is an effective method to prevent the spreading of corrosion in affected

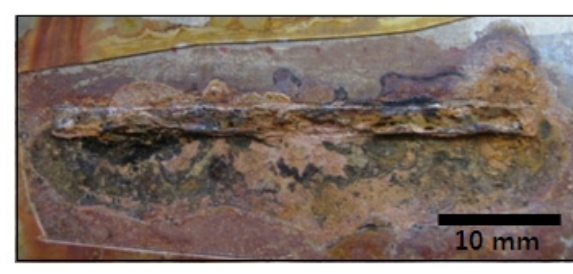

(a)

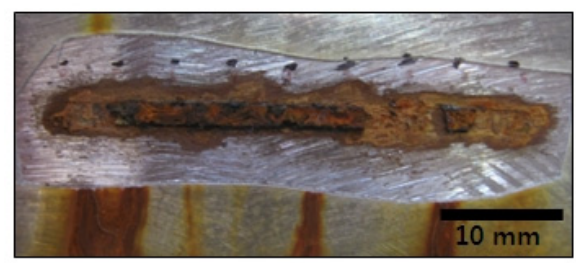

(c)

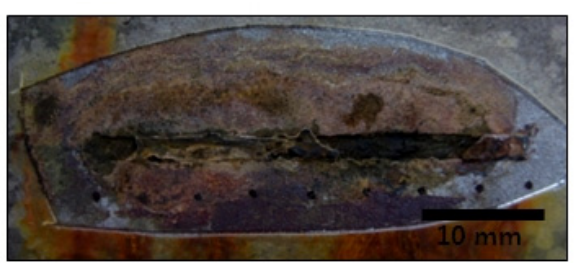

(b)

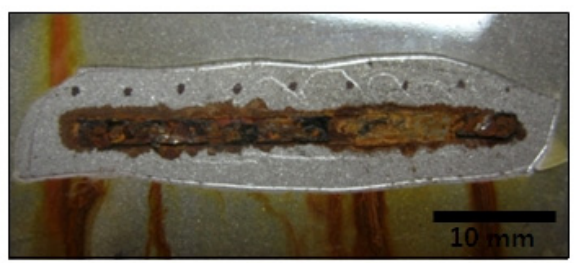

(d)

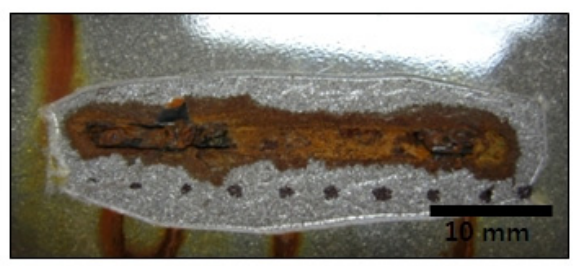

(e)

Fig. 11. Photographs of undercutting for specimens taken from the salt spray test: (a) untreated, (b) SB treated (c) PT treated, (d) GS treated, and (e) GL treated. 
areas.

\subsection{Effects of surface treatment on conosion protection as measured by EIS}

The corrosion resistance of epoxy-coated steel with and without surface treatments was examined by EIS combined with hygrothermal cyclic testing. The EIS spectrum measured for the untreated epoxy-coated steel as a function of the hygrothermal cycles showed an impedance value of $\log / \mathrm{Z} /$ at $0.01 \mathrm{~Hz}$ that dramatically decreased from 2.17 $\times 10^{10} \Omega \mathrm{cm}^{2}$ to $6.43 \times 10^{7} \Omega \mathrm{cm}^{2}$ after 5 hygrothermal test cycles, after which it slightly decreased to $1.44 \times 10^{7}$ $\Omega \mathrm{cm}^{2}$ after 27 cycles (Fig. 12). Fig. 13a shows the EIS spectrum as a function of the hygrothermal cycle number for SB-treated epoxy-coated steel. The decreasing trend in the impedance value with respect to the hygrothermal cycle for the SB-treated epoxy-coated steel was similar to that exhibited by the untreated epoxy-coated steel. The impedance value $/ \mathrm{Z} /$ at $0.01 \mathrm{~Hz}$ decreased from $3.97 \times$ $10^{10} \Omega \mathrm{cm}^{2}$ to $1.32 \times 10^{8} \Omega \mathrm{cm}^{2}$ after 27 cycles. Evidently, the decrease in the impedance value was lower than that

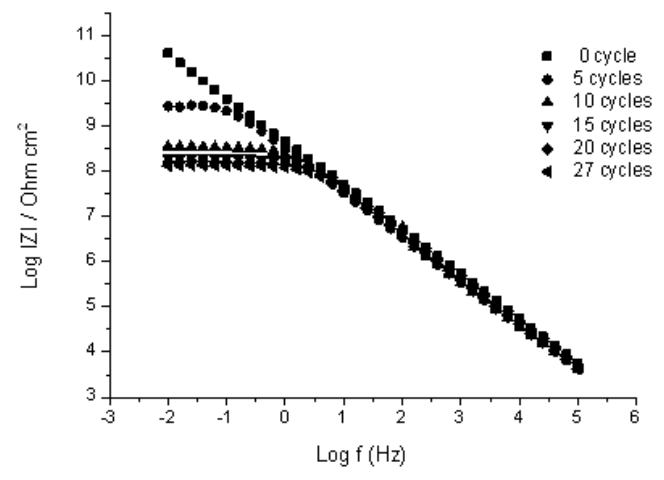

(a)

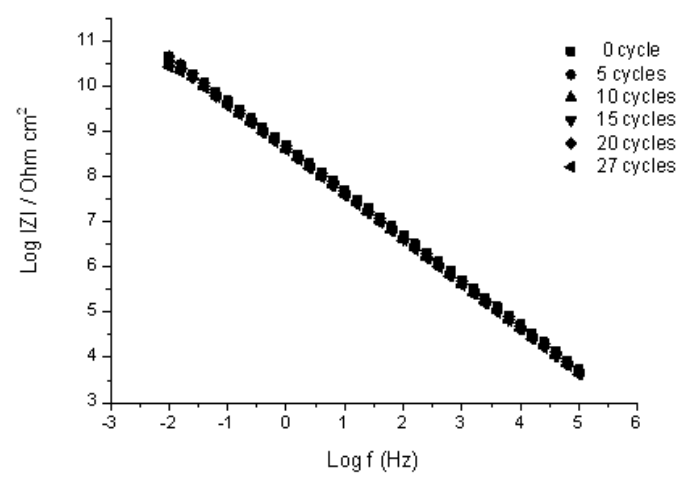

(c) in the untreated epoxy-coated steel.

Fig. 13b shows the EIS spectrum as a function of the cycle number in the hygrothermal testing of PT-treated epoxy-coated steel. The decreasing trend in the impedance value as a function of the hygrothermal cycle number was

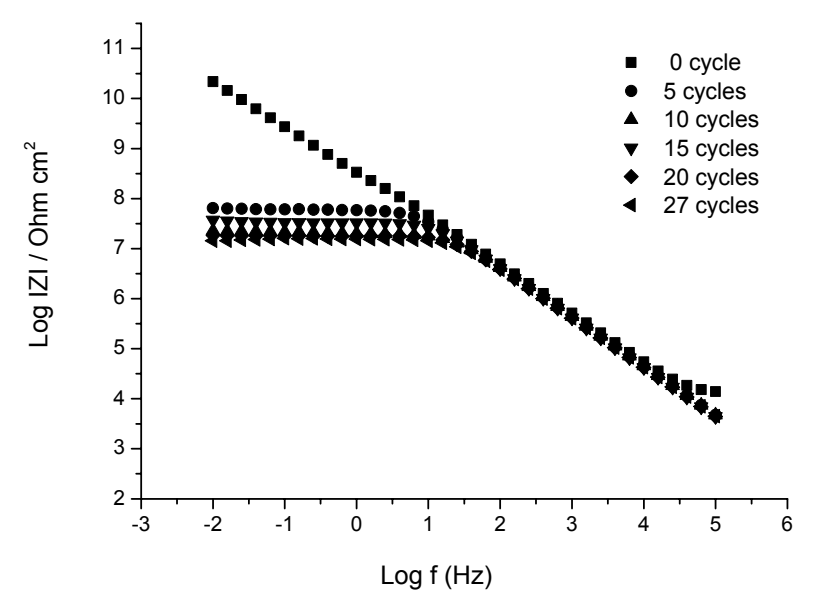

Fig. 12. EIS spectra for untreated epoxy coating with increasing hygrothermal cycles.

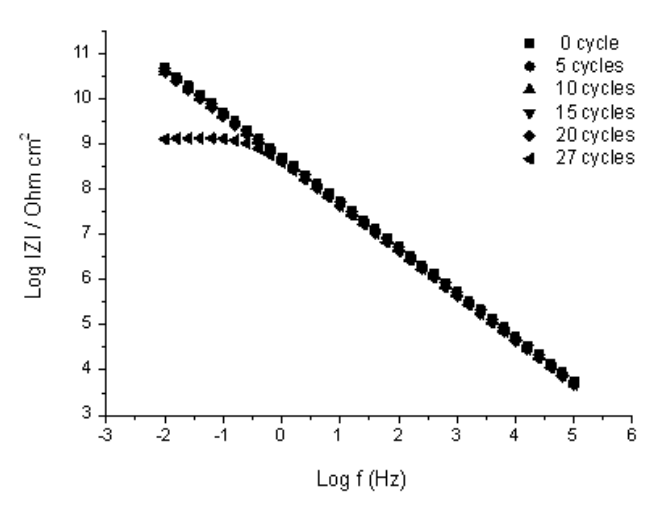

(b)

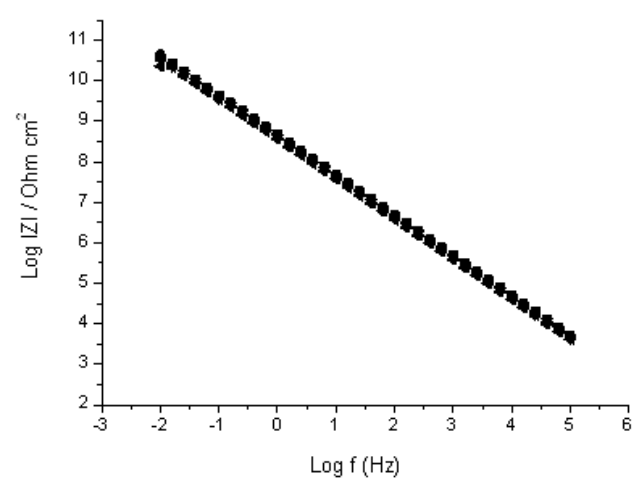

(d)

Fig. 13. EIS spectra for treated epoxy-coated surfaces with increasing hygrothermal cycle: (a) SB treated, (b) PT treated, (c) GS treated, and (d) GL treated. 


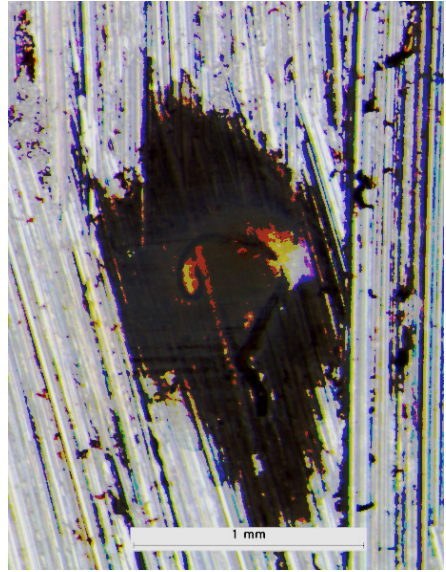

Fig. 14. Optical microscopy image of localized corrosion at the epoxy coat/carbon steel interface of PT treated steel after 27 cycles of hygrothermal testing.

different from that observed in the untreated epoxy-coated and SB-treated surfaces. The impedance value /Z/ at 0.01 $\mathrm{Hz}$ was almost constant at approximately $4 \times 10^{10} \Omega \mathrm{cm}^{2}$ after 20 cycles and then decreased to $1.26 \times 10^{9} \Omega \mathrm{cm}^{2}$ after 27 cycles. The decreased impedance value after 27 cycles seems to be caused by the occurrence of localized corrosion on the steel surface and might involve corrosion by foreign materials trapped in the rough profile generated during the power tool treatment (Fig. 14). This demonstrated that the power tool treatment was very effective in providing good adhesion and good corrosion resistance but that the removal of trapped foreign materials, such as loose abrasive particles, within the profile should be carefully considered.

Fig. 13c and d show the EIS spectrum as a function of the cycle number in the hygrothermal testing of GSand GL-treated epoxy-coated steel. The impedance value as a function of the hygrothermal cycle number remained constant at $4 \times 10^{10} \Omega \mathrm{cm}^{2}$ after 27 cycles.

In summary, this indicates that the corrosion protection of epoxy-coated carbon steel agreed well with the adhesion strength and, consequently, caused less undercutting under corrosive conditions.

\section{Conclusions}

Higher adhesion strength of epoxy-coated carbon steel was achieved by steel grit blasting methods after hygrothermal cyclic testing. It clearly indicated that the sharp and rough surface generated by grit blasting showed effective mechanical interlocking or keying with the epoxy coating and the GS-treated carbon steel showed uniform and sharp surface profile as well as high adhesion strength and less undercutting in the epoxy coated carbon steel, resulting in a good corrosion protection performance.

\section{Acknowledgement}

Financial support by pukyong national university is gratefully acknowledged.

\section{References}

1. C. A. May, Epoxy Resins; Chemistry and Technology, Marcel Dekker, New York (1988).

2. T. M. Goulding, Epoxy Resin Adhesives, in: Handbook of Adhesive Technology, p. 531, A. Pizzi, K. L. Mittal, Eds., Marcel Dekker, New York (1994),.

3. M. T. Aronhime and J. K. Gillham, J. Appl. Polym. Sci., 32, 3589 (1986).

4. J. M. Zhou and J. P. Lucas, Polymer, 40, 5505 (1999).

5. L. Nunez, M. Villanueva, F. Fraga, and M. R Nunez, J. Appl. Polym. Sci., 74, 353 (1999).

6. G. Z. Xiao and M. E. R Shanahan, J. Appl. Polym. Sci., 65, 449 (1997).

7. G. W. Critchlow and D. M Brewis, Int. J. Adhesion Adhesives, 15, 173 (1995).

8. Y. Gilibert, G. Verchery. Infuence of surface roughness on mechanical properties of joints, : Plenum Press, New York, 1982.

9. C. W. Jennings, Am Chem Soc Div., Org. Chem, 31, 184 (1971).

10. J. P. Sargent, Int. J. Adhes Adhes, 14, 21 (1994).

11. T. R. Katona, S. C. Batterman, Int. J. Adhes Adhes, 3, 85 (1983).

12. K. Matsui, J. Adhesion, 10, 81 (1990).

13. A. F. Harris, A. Beevers, Conf Proc Structural Adhesives in Engineering V. Bristol: Institute of Materials (1998).

14. E. Sancaktar and R. Gomatam, J. Adhes. Sci. Technol., 15, 97 (2001).

15. M. Shahid and S. A. Hashim, Int J. Adhes. Adhes., 22, 235 (2002).

16. Gordon P. Bierwagen, L. He, J. Li, L. Ellingson, and D. E. Tallman, Prog. Org. Coat., 39, 67 (2000).

17. L. Valentinelli, J. Vogelsang, H. Ochs, and L. Fedrizzi, Prog. Org. Coating, 45, 405 (2002).

18. L. Fedrizzi, A. Bergo, F. Deflorian, and L. Valentinelli, Prog. Org. Coat., 48, 271 (2003).

19. S. Touzain, Q. Le Thu, and G. Bonnet, Prog. Org. Coat., 52, 311 (2005).

20. L. Fedrizzi, A. Bergo, and M. Fanicchia, Electrochim. Acta, 51, 1864 (2006).

21. ASTM D4541 - 09 Standard Test Method for Pull-Off Strength of Coatings Using Portable Adhesion Testers.

22. ASTM B117 - 11 Standard Practice for Operating Salt Spray (Fog) Apparatus.

23. NORSOK STANDARD M-501 Surface preparation and Protective coating, (2004). 